\title{
Prospects for Coalbed Methane and Shale Gas in a Carbon-Constrained World: A Preliminary Analysis
}

\author{
Takayuki Takeshita \\ Transdisciplinary Initiative for Global Sustainability, The University of Tokyo, Tokyo, Japan \\ Email: takeshita@ir3s.u-tokyo.ac.jp
}

Received April 16, 2013; revised June 2, 2013; accepted April 24, 2013

\begin{abstract}
Using a regionally disaggregated global energy system model with a detailed treatment of the natural gas resource base, this paper analyzes the competitiveness of coalbed methane and shale gas in the global primary energy mix and the cost-optimal pattern of their production in regional detail over the period 2010-2050 under a constraint of halving global energy-related $\mathrm{CO}_{2}$ emissions in 2050 compared to the 2000 level. It is first shown that neither coalbed methane nor shale gas could become an important fuel in the global primary energy mix throughout the time horizon, although each of them could become an important source of world natural gas production from around 2030 onwards. It is then shown that unlike findings of previous studies, coalbed methane would be more attractive than shale gas as a primary energy source globally under the $\mathrm{CO}_{2}$ constraint used here. The results indicate that North America continues to be the world's largest coalbed methane producer until 2030, after which China overtakes North America and retains this position until 2050. Also, India, Russia, South Africa, and Australia contribute noticeably to world coalbed methane production. The results also indicate that North America continues to dominate world shale gas production until 2040, after which a number of world regions, notably India, Europe, and China, begin to participate visibly in world shale gas production.
\end{abstract}

Keywords: Coalbed Methane; Shale Gas; $\mathrm{CO}_{2}$ Mitigation; Regionally Detailed Analysis; Global Energy System Model

\section{Introduction}

Driven by the unconventional gas revolution that has taken hold in North America in recent years, world unconventional gas production has been increasing steadily. Already, the rapidly expanding development of unconventional gas has reshaped the US gas market and substantially affected the global gas market. Given the large resource base of unconventional gas and the growing demand for affordable, clean natural gas worldwide, this trend is likely to continue in the future. As a consequence, it is well possible that unconventional gas will become one of the most important fuels in the future global primary energy mix, and that unconventional gas production will have a huge impact on the future global energy landscape.

Under these circumstances, unconventional gas and its prospects are receiving significant attention globally. Thus, several studies have so far constructed quantitative scenarios of future unconventional gas production. Among all previous related studies, the special report in the International Energy Agency's (IEA) World Energy Outlook 2011 [1] seems to be the most elaborate one. It presented projections of world natural gas production by region and world natural gas production by type through to 2035. It obtained two important findings relating to unconventional gas production. First, the share of unconventional gas in total global gas supplies will rise continuously, reaching $24 \%$ in 2035 . Second, most of the increase in unconventional gas production comes from shale gas and coalbed methane.

However, there are some drawbacks in this IEA study. First, projections were performed without the international target to avoid dangerous climate change. The results of the projections suggest the long-term global average temperature rise of over 3.5 degrees Celsius above pre-industrial levels. Second, it does not provide a regional split of the production of each type of unconventional gas over the projection period. Third, projections were performed over the period to 2035, so it is unable to assess the long-term prospects for unconventional gas.

In this context, this paper explores the prospects for coalbed methane and shale gas in regional detail over the period to 2050 under a stringent climate stabilization constraint (i.e., a halving of global energy-related $\mathrm{CO}_{2}$ emissions in 2050 compared to the 2000 level). In the first step, the competitiveness of coalbed methane and shale gas in the global primary energy mix under this constraint is assessed over the long term. In the second step, the cost-optimal global pattern of their production under this constraint is derived in regional detail over the 
long term. Due to space limitations, the focus of this paper is confined to the competitiveness of coalbed methane and shale gas and their production pattern only. These analyses are done by using a regionally disaggregated global energy system model with 70 regions (REDGEM70) [2,3], which is characterized by a detailed technological representation.

\section{Methodology}

\subsection{Overview of the REDGEM70 Model}

REDGEM70 is a technology-rich, bottom-up global energy systems optimization model formulated as an intertemporal linear programming problem (see [3] for a schematic representation of the structure of the model). With a $5 \%$ discount rate, the model is designed to determine the cost-optimal energy strategy (e.g., the cost-optimal choice of technologies and fuels) from 2010 to 2050 at 10-year intervals for each of 70 world regions so that total discounted global energy system costs are minimized under constraints on the satisfaction of exogenously given energy end-use demands, the availability of primary energy resources, material and energy balances, the maximum market growth rates of new technologies and fuels, etc. In the model, price-induced energy demand reductions and energy efficiency improvements, fuel switching to less carbon-intensive fuels, and $\mathrm{CO}_{2}$ capture and storage in geologic formations are the three options for $\mathrm{CO}_{2}$ emissions reduction.

Furthermore, in the current version of the model used in this study, there is also a constraint that global en- ergy-related $\mathrm{CO}_{2}$ emissions in 2050 are to be halved compared to the 2000 level. This constraint is imposed because the Intergovernmental Panel on Climate Change (IPCC) has concluded that a $50 \%$ to $80 \%$ reduction of global $\mathrm{CO}_{2}$ emissions by 2050 compared to the 2000 level can limit the long-term global mean temperature rise to 2.0 degrees Celsius above pre-industrial levels [4], which is now recognized as the ultimate goal by most world leaders and experts. The model has a full flexibility in where and how $\mathrm{CO}_{2}$ emissions reduction is achieved to meet this constraint.

As described above, REDGEM70 uses 70 world regions. Figure 1 shows how the 70 world regions are defined in the model. These 70 regions are categorized into "energy production and consumption regions" and "energy production regions”. The whole world was first divided into the 48 energy production and consumption regions to which future energy end-use demands are allocated. The 22 energy production regions, which are defined as geographical points, were then distinguished from the energy production and consumption regions to represent the geographical characteristics of the areas endowed with large amounts of fossil energy resources. While the 48 energy production and consumption regions cover the global final energy consumption, all the energy-related activities except final energy consumption are conducted in each of the two region types in the model. Such a detailed regional disaggregation enables the explicit consideration of regional characteristics in terms of energy resource supply, energy demands, geography, and climate.

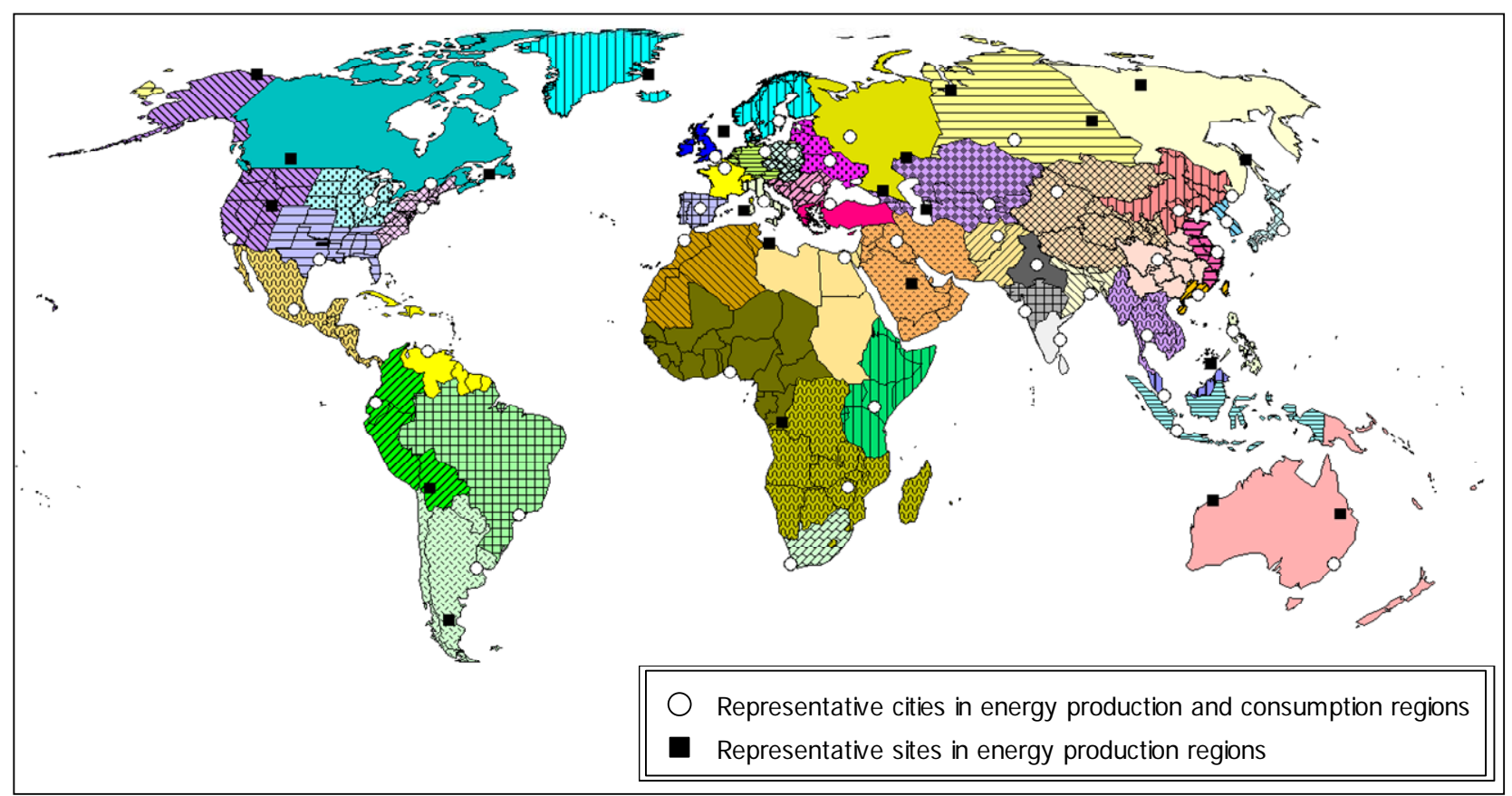

Figure 1. Regional disaggregation of REDGEM70. 
Future trajectories for energy end-use demands were estimated as a function of those for socio-economic driving forces such as population and income in the intermediate B2 scenario developed by [5]. Allocation of the energy end-use demand estimates to the 48 energy production and consumption regions was done by using country- and state-level statistics/estimates (and projections if available) on population, income, geography, energy use by type, and transport activity by mode, and by taking into account the underlying storyline of the B2 scenario that regional diversity might be somewhat preserved throughout the 21st century.

Assumptions on the availability and extraction cost of fossil energy resources and uranium resources were derived from [6] and [7], respectively. A detailed description of the modeling of the natural gas resource base is given in Section 2.2. There is one important note regarding the treatment of exhaustible resources in this modeling analysis. To avoid excessive exploitation of exhaustible primary energy resources in the first half of the century, the model was actually run over the period 2010-2100, and then the results of this simulation are shown for the period 2010-2050.

For non-biomass renewable resources, electricity supply potentials and electricity generation costs by world region are exogenous inputs to the model, which were obtained from $[8,9]$. For biomass resources, the model considers not only terrestrial biomass, but also waste biomass. Data for these biomass resources are provided in [10]. These resource availability estimates were then allocated to the 70 model regions by using country-, state-, and site-level statistics/estimates.

REDGEM70 considers the entire supply chain of natural gas, which includes natural gas production, interregional natural gas transportation by pipeline or liquefied natural gas tanker ship, natural gas storage, its conversion into secondary energy, intraregional natural gas distribution, and its final supply at retail sites. In the model, natural gas can be converted into high- and lowtemperature heat, electricity, hydrogen, methanol, dimethyl ether, and Fischer-Tropsch synfuels. It can also be used as a fuel for road vehicles (excluding motorized two-wheelers), large ships, and aircraft and feedstock for industrial use.

\subsection{Modeling of the Natural Gas Resource Base}

In addition to conventional gas, REDGEM70 considers three types of unconventional gas, including coalbed methane, shale gas, and other unconventional gas such as tight gas and deep gas. Gas hydrates are not included because it is presently unclear if and when their potential can ever be used [11]. The resource base estimates of conventional gas and these three types of unconventional gas by each of 18 world regions are taken from [6]. Fur- thermore, the estimates of the potential for enhanced coalbed methane (ECBM) recovery from $\mathrm{CO}_{2}$ injection by each of seven world regions are taken from [12,13]. The global resource base of conventional gas, coalbed methane, shale gas, and other unconventional gas amounts to 12,213 exajoules, 7,520 exajoules, 9,281 exajoules, and 13,016 exajoules, respectively.

The conventional gas resource base estimates by each of 18 world regions were allocated to the 70 model regions by using data from $[11,14,15]$. The stepwise supply cost curves of conventional gas (consisting of three steps) were then developed for each of the 70 model regions from global and regional data on the range of conventional gas production costs, which do not include taxes or royalties [1,6,16-18]. Figure 2 illustrates the resulting aggregate global conventional gas supply cost curve.

Following the approach taken by [16], the coalbed methane resource base estimates (including those of the potential for ECBM recovery from $\mathrm{CO}_{2}$ injection) by each world region were allocated to the 70 model regions by linking its regional distribution to that of the anthracite and bituminous coal resource base, which was estimated from $[12,19,20]$. Similar to the development of the conventional gas supply cost curves above, the stepwise supply cost curves of coalbed methane (consisting of three steps) were then developed for each of the 70 model regions from global and regional data on the range of coalbed methane production costs, which do not include taxes or royalties $[1,6,12,13,16-18]$. Regional variation in production costs of coalbed methane (excluding ECBM) was estimated using regional data on them $[1,16,18]$ and assuming that they are lower for regions with rich coalbed methane production experience (implying the existence of production skills and supply infrastructure) and the large coalbed methane resource base. Figure 2 illustrates the resulting aggregate global coalbed methane supply cost curve.

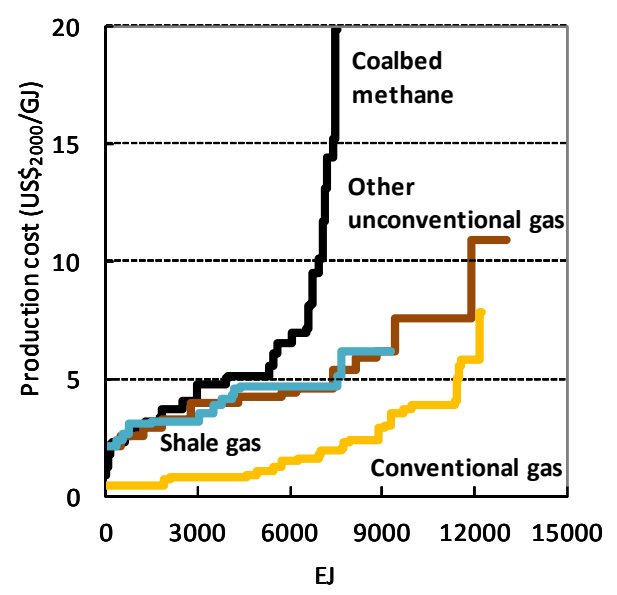

Figure 2. Aggregate world supply cost curves for conventional and unconventional natural gas. 
For shale gas, a lack of comprehensive world-wide resource potential data makes it difficult to derive accurate estimates of the regional distribution of its resource base by the 70 model regions. Specifically, there seem not to be reliable shale gas resource potential data for regions except the US and the 32 countries examined by [21]. Accordingly, the estimates of the shale gas resource base in the US taken from [6] were allocated to the six US regions of the model by using data from [18,22,23]. On the other hand, the estimates of the shale gas resource base in the other world regions taken from [6] were allocated to the 64 model regions by using data from [21,22] and by following the assumption made by [16] that its regional distribution is linked to that of the in-place shale volume given by [16]. The stepwise supply cost curves of shale gas (consisting of three steps) were then developed for each of the 70 model regions from global and regional data on the range of shale gas production costs, which do not include taxes or royalties [1,6,16-18,23]. Regional variation in shale gas production costs was estimated using regional data on them $[16,18,23]$ and assuming that they are lower for regions with rich shale gas production experience. Figure 2 illustrates the resulting aggregate global shale gas supply cost curve.

Following the approach taken by [16], the estimates of the other unconventional gas resource base by each of 18 world regions were allocated to the 70 model regions by linking its regional distribution to that of the conventional gas resource base. The stepwise supply cost curves of other unconventional gas (consisting of three steps) were then developed for each of the 70 model regions from global and regional data on the range of its production costs, which do not include taxes or royalties [1,6,16-18]. Regional variation in its production costs was estimated using regional data on them $[1,16,18]$ and assuming that they are lower for regions with rich production experience of other unconventional gas and its large resource bases. Figure 2 illustrates the resulting aggregate global supply cost curve of other unconventional gas.

In the last step, royalties are added to gas production costs described above. Royalties from gas production were estimated at US\$2000 0.59 per gigajoule of gas, compared to US\$2000 1.77 per gigajoule of crude oil and $\mathrm{US}_{2000} 0.44$ per gigajoule of coal [19]. This sum is regarded as actual gas production costs and is used as an exogenous input to the model. In the model, taxes are not included as part of energy system costs.

\section{Results and Discussion}

\subsection{Competitiveness of Coalbed Methane and Shale Gas}

Figure 3 shows the evolution of the world total primary

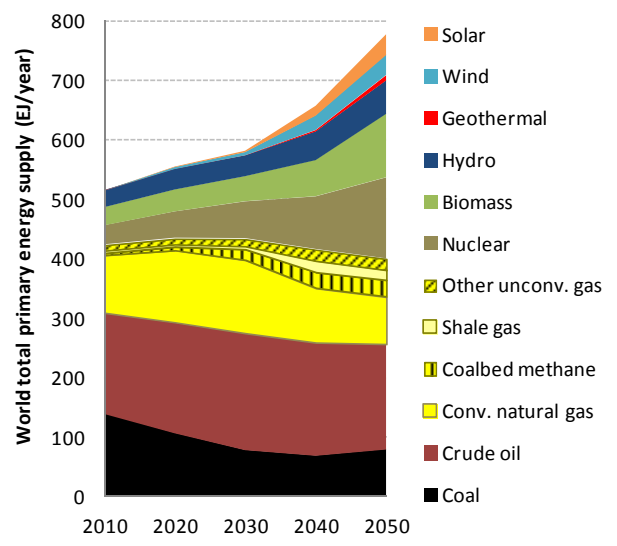

Figure 3. World total primary energy supply.

energy supply (TPES). The substitution accounting method is used for reporting TPES. It can be seen that natural gas continues to be an important primary energy source throughout the time horizon. The share of natural gas in the world TPES overtakes that of coal by 2020 to become the second-most important fuel in the global primary energy mix from 2020 onwards. The share of natural gas in the world TPES increases until 2030 but begins to decrease thereafter, reaching $18.4 \%$ in 2050 . Also, in absolute terms, world natural gas production reaches its peak in 2030 with a slightly declining trend thereafter. Under the stringent $\mathrm{CO}_{2}$ emissions reduction constraint, non-fossil fuels (such as nuclear and renewables) account for an increasing share in the world TPES at the expense of fossil fuels.

Although the share of unconventional gas in world natural gas production is small in the early time periods, unconventional gas becomes increasingly competitive over time. Its share of world natural gas production increases from $15.1 \%$ in 2010 to $44.6 \%$ in 2050, implying that about half of world natural gas production comes from unconventional sources in 2050. Such an increased participation of unconventional gas leads to an increase in its share of the global primary energy mix: the share of unconventional gas in the world TPES increases from $3.3 \%$ in 2010 to $9.8 \%$ in 2040 and then decreases to $8.2 \%$ in 2050. This decline in the share of unconventional gas in 2050 is due to the declining share of natural gas in the world TPES in the second half of the time horizon. It can therefore be argued that unconventional gas could constitute one of the pillars of the global primary energy mix from around 2030 onwards.

Among all types of unconventional gas sources, other unconventional gas (mainly tight gas) has the largest share of world unconventional gas production until 2020. After that, coalbed methane continues to be the most important unconventional gas source worldwide: its share of world natural gas production increases from $2.7 \%$ in 2010 to $19.4 \%$ in 2050 . Over the period 2040 - 
2050, shale gas remains the second-most important unconventional gas source worldwide: its share of world natural gas production increases from 4.3\% in 2010 to $12.0 \%$ in 2050 .

This finding is different from that of previous studies (e.g., [1]), which projected that shale gas would become the largest unconventional gas source worldwide from around 2020 onwards. However, the above finding of this study is plausible for three reasons. First, as shown in Figure 2, the production cost of coalbed methane is almost the same or even slightly lower than that of shale gas, as long as their cumulative production throughout the time horizon is below the level achieved in this study (i.e., 799.7 EJ for coalbed methane and 523.5 EJ for shale gas). Second, under the stringent $\mathrm{CO}_{2}$ emissions reduction constraint, $\mathrm{CO}_{2}$ is priced at a sufficient level to offset part of the production cost of ECBM recovery using $\mathrm{CO}_{2}$ sequestration, which makes coalbed methane production attractive. In fact, the results show that $\mathrm{CO}_{2}-$ ECBM is developed on a large scale from the initial stage of coalbed methane production. Third, China and India are projected to account for a significant share of world natural gas demand in the long term toward 2050 (e.g., $[1,24])$, and these countries are estimated to be endowed with much larger amounts of the coalbed methane resource base than those of the shale gas resource base [6]. Therefore, the supply of coalbed methane is more cost-effective than that of shale gas in these countries because of the low demand for gas transportation, which represents a large share of total natural gas supply cost.

It is important to note that coalbed methane and shale gas play only marginal roles in the world TPES, as shown in Figure 3. The share of coalbed methane and shale gas in the world TPES increases from $0.6 \%$ in 2010 to $3.6 \%$ in 2050 for the former and from $0.9 \%$ in 2010 to $2.2 \%$ in 2050 for the latter. To summarize, these results mean that neither coalbed methane nor shale gas would become one of the important fuels in the global primary energy mix over the period to 2050 under the stringent $\mathrm{CO}_{2}$ emissions reduction constraint, although each of them would have a large share of world natural gas production from around 2030 onwards under this constraint.

\subsection{Cost-Optimal Pattern of Coalbed Methane and Shale Gas Production}

Figures 4 and 5 show the regional breakdown of the world production of coalbed methane and shale gas, respectively. The regional classification used in this study is identical to that of [5]. North America (predominantly the US) continues to be the biggest supply source of coalbed methane until 2030. After that, Centrally Planned Asia (predominantly China) overtakes North America to become the world's largest coalbed methane producer. From around 2030 onwards, coalbed methane production

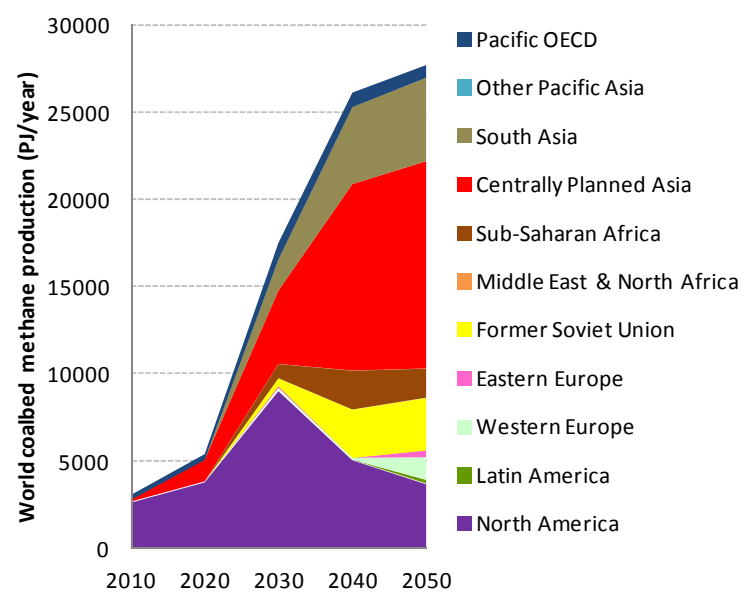

Figure 4. World coalbed methane production by the 11 world regions.

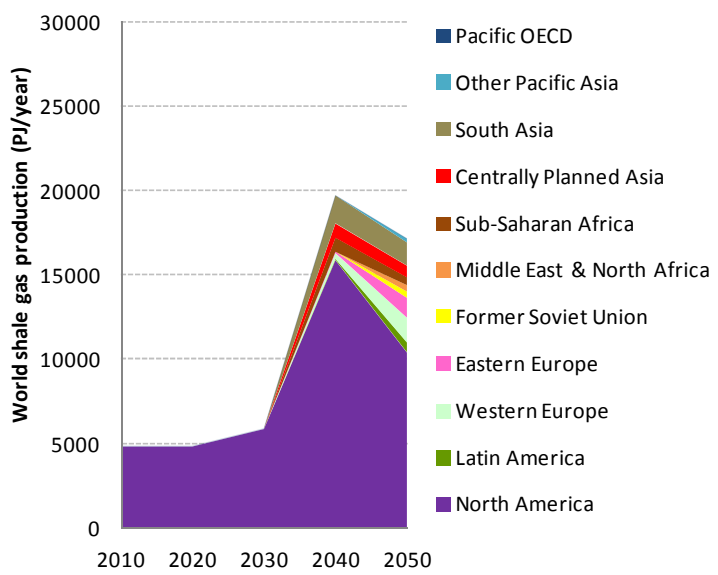

Figure 5. World shale gas production by the 11 world regions.

becomes more spatially dispersed. Besides North America and Centrally Planned Asia, South Asia (predominantly India), the Former Soviet Union (predominantly Russia), Sub-Saharan Africa (predominantly South Africa), Western Europe, and Pacific OECD (predominantly Australia) make a noticeable contribution to world coalbed methane production.

In contrast, North America (predominantly the US) continues to dominate world shale gas production throughout the time horizon. However, a number of world regions, notably South Asia, Western Europe, Eastern Europe, and Centrally Planned Asia, begin to have a visible participation in world shale gas production around 2040. The combined share of the world regions except North America in world shale gas production reaches only $39.3 \%$ in 2050 . This implies that the US is likely to retain its position as the world's largest shale gas producer at least until the middle of the century.

Now, the results are described in more regional detail. As an example, Figure 6 shows the world natural gas production by region and by source for 2050 . 
The cost-optimal pattern of coalbed methane production at the regional level is summarized as follows. In 2020, there are five major coalbed methane-producing regions in the world: 1) basins in the Rocky Mountains (e.g., San Juan, Raton, and Powder River), 2) the Western Canadian Sedimentary Basin (including Alberta and British Columbia), 3) the northern and central Appalachian basins, 4) basins in northern China (e.g., Ordos and Qingshui), and 5) basins in eastern Australia. In 2030, besides the above regions, eastern India and South Africa become major coalbed methane-producing regions in the world. In 2040, central, eastern, and western China (e.g., Junggar), Russia (e.g., Kuznetsk), western and southern India, and the southern part of Africa except South Africa (e.g., Botswana) join the major coalbed methane-producing regions in the world, and some European countries (e.g., Germany and Czech Republic) join them in 2050 as shown in Figure 6.

On the other hand, the cost-optimal pattern of shale gas production at the regional level is summarized as follows. Over the period to 2030, the southeastern and northeastern parts of the US (e.g., Barnett, Haynesville, Fayetteville, Woodford, and Marcellus) dominate world shale gas production, while small-scale shale gas production is carried out in the Western Canadian Sedimentary Basin (e.g., Horn River and Montney) and basins in the Rocky Mountains. In 2040, besides the above regions, India (e.g., West Bengal), inland central China (i.e., Sichuan), South Africa (i.e., Karoo), and some European countries (e.g., France and Poland) become major shale gas-producing regions in the world. In 2050 as shown in Figure 6, other European countries and the southern part of Latin America (e.g., Argentina) join them.

\section{Conclusions}

In this paper, the regionally disaggregated global energy system model with a detailed treatment of the conventional and unconventional natural gas resource base has been used to explore the long-term prospects for coalbed methane and shale gas in regional detail over the period to 2050 under the constraint of halving global energyrelated $\mathrm{CO}_{2}$ emissions in 2050 compared to the 2000 level. Their competitiveness in the global primary energy mix under this constraint has first been assessed over the period to 2050. The cost-optimal pattern of their production under this constraint has then been derived in regional detail over the period to 2050. The major findings and implications can be summarized as follows.

First, neither coalbed methane nor shale gas could become an important fuel in the global primary energy mix over the period to 2050 under the stringent $\mathrm{CO}_{2}$ emissions reduction constraint. The share of coalbed methane and shale gas in the world TPES would increase over time but reach only 3.6\% and 2.2\%, respectively, in 2050 . However, each of them would become an increasingly important source of world natural gas production over time. The share of coalbed methane and shale gas in world natural gas production would increase over time and reach $19.4 \%$ and $12.0 \%$, respectively, in 2050 .

Second, in contrast to findings of previous studies, coalbed methane would become a more attractive fuel than shale gas at the global level from around 2020 onwards. One main reason is that $\mathrm{CO}_{2}$-ECBM techniques would be deployed on a large scale as a means of reducing $\mathrm{CO}_{2}$ emissions under the stringent $\mathrm{CO}_{2}$ emissions reduction constraint, which would provide a great incentive for increased coalbed methane production. Another

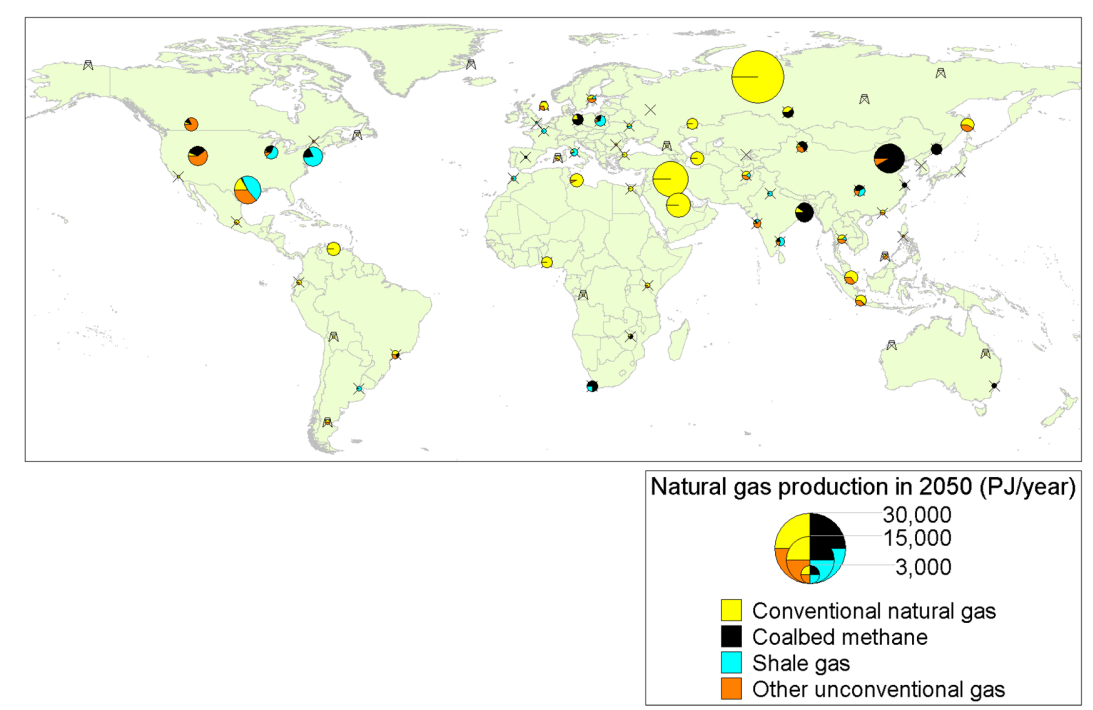

Figure 6. World natural gas production by region and by source in $2050^{\mathrm{a}}$.

a. Towers indicate representative sites in energy production regions, while crosses indicate representative cities in energy production and consumption regions. 
main reason is that the world's major coalbed methane-rich regions are located geographically close to the world's major natural gas consumption regions (i.e., China and India). This helps to reduce natural gas transportation cost and to improve the overall economics of natural gas supply.

Third, in the cost-optimal coalbed methane production pattern derived from the model, North America (mainly the Rocky Mountain and Appalachian regions of the US) remains the world's largest coalbed methane producer until 2030, after which Centrally Planned Asia (mainly northern China) overtakes North America and continues to be the world's largest coalbed methane producer. From around 2030 onwards, South Asia (mainly eastern India), the Former Soviet Union (mainly Kuznetsk), Sub-Saharan Africa (mainly South Africa), and Pacific OECD (mainly eastern Australia) also contribute noticeably to world coalbed methane production. On the other hand, in the cost-optimal shale gas production pattern derived from the model, North America (mainly the southeastern and northeastern parts of the US) continues to dominate world shale gas production until 2040. After that, South Asia (mainly India), Western and Eastern Europe (mainly Poland and France), and Centrally Planned Asia (mainly Sichuan) also participate visibly in world shale gas production.

It must be emphasized that coalbed methane and shale gas could play a substantial role in diversifying natural gas supply sources, and thus in improving energy security. The widespread market penetration of coalbed methane and shale gas could make a large contribution to reducing the world's dependence on conventional gas in the Middle East and Russia. They have a potential for representing the most part of natural gas supply in countries such as the US, China, and India in the long term. It should be noted, however, that not only the realization of the potential for coalbed methane and shale gas outside North America, but also their ever increasing production in North America remains actually highly uncertain. To receive the full benefits of coalbed methane and shale gas, numerous obstacles (such as large volumes of water use, negative environmental impacts, and safety risks) must be overcome.

\section{REFERENCES}

[1] IEA, "World Energy Outlook 2011 Special Report: Are We Entering A Golden Age of Gas?” IEA, Paris, 2011.

[2] T. Takeshita and K. Yamaji, "Important Roles of Fischer-Tropsch Synfuels in the Global Energy Future," Energy Policy, Vol. 36, No. 8, 2008, pp. 2791-2802. doi:10.1016/j.enpol.2008.02.044
[3] T. Takeshita, "Assessing the Co-Benefits of $\mathrm{CO}_{2}$ Mitigation on Air Pollutants Emissions from Road Vehicles," Applied Energy, Vol. 97, 2012, pp. 225-237. doi:10.1016/j.apenergy.2011.12.029

[4] B. Metz, O. Davidson, P. Bosch, R. Dave and L. Meyer, Eds., "Climate Change 2007: Mitigation,” Contribution of Working Group III to the 4th Assessment Report of the IPCC, Cambridge University Press, New York, 2007.

[5] International Institute for Applied Systems Analysis, “GGI Scenario Database,” 2007.

http://www.iiasa.ac.at/Research/GGI/DB/

[6] H.-H. Rogner, "Energy Resources and Potentials,” In: T. B. Johansson, A. Patwardhan, N. Nakicenovic and L. G. Echeverri, Eds., Global Energy Assessment, Cambridge University Press, New York, 2012, pp. 425-512.

[7] Organization for Economic Co-Operation and Development (OECD) Nuclear Energy Agency and International Atomic Energy Agency, "Uranium 2001: Resources, Production and Demand,” OECD, Paris, 2002.

[8] M. Hoogwijk and W. Graus, "Global Potential of Renewable Energy Sources: A Literature Assessment," ECOFYS, Utrecht, The Netherlands, 2008.

[9] W. Turkenburg, "Renewable Energy,” In: T. B. Johansson, A. Patwardhan, N. Nakicenovic and L. G. Echeverri, Eds., Global Energy Assessment, Cambridge University Press, New York, 2012, pp. 761-900.

[10] T. Takeshita, “A Strategy for Introducing Modern Bioenergy into Developing Asia to Avoid Dangerous Climate Change,” Applied Energy, Vol. 86, 2009, pp. S222-S232. doi:10.1016/j.apenergy.2009.04.023

[11] BGR, "Reserves, Resources and Availability of Energy Resources 2010,” BGR, Hannover, Germany, 2010.

[12] Research Institute of Innovative Technology for the Earth, "Study Project for Implementation Planning of the New Earth Program,” New Energy and Industrial Technology Development Organization, Tokyo, 2002.

[13] IPCC, "Special Report on Carbon Dioxide Capture and Storage,” Cambridge University Press, Cambridge, 2005.

[14] US Geological Survey (USGS), "USGS World Petroleum Assessment 2000: Description and Results,” USGS, Washington DC, 2000.

[15] USGS, "Circum-Arctic Resource Appraisal: Fact Sheet 2008-3049,” USGS, Washington DC, 2008.

[16] H.-H. Rogner, "An Assessment of World Hydrocarbon Resources," Annual Review of Energy and the Environment, Vol. 22, 1997, pp. 217-262. doi:10.1146/annurev.energy.22.1.217

[17] IEA, “World Energy Outlook 2009,” IEA, Paris, 2009.

[18] MIT Energy Initiative, "The Future of Natural Gas: An Interdisciplinary MIT Study,” Massachusetts Institute of Technology, Cambridge, MA, 2011.

[19] Y. Masuoka, "Possibility Evaluation of the Fluid Fuel Use with Regionally Disaggregated Global Energy Model," Master Thesis, The University of Tokyo, Tokyo, 2003. 
[20] World Energy Council (WEC), “2010 Survey of Energy Resources,” WEC, London, 2010.

[21] US Energy Information Administration, "World Shale Gas Resources: An Initial Assessment of 14 Regions Outside the United States," US Department of Energy, Washington DC, 2011.

[22] C. Boyer, B. Clark, V. Jochen, R. Lewis and C. K. Miller,
“Shale Gas: A Global Resource,” Oilfield Review, Vol. 23, No. 3, 2011, pp. 28-39.

[23] K. B. Medlock, A. M. Jaffe and P. R. Hartley, "Shale Gas and U.S. National Security,” James A. Baker III Institute for Public Policy, Rice University, Houston, TX, 2011.

[24] IEA, “Energy Technology Perspectives 2010,” IEA, Paris, 2010. 